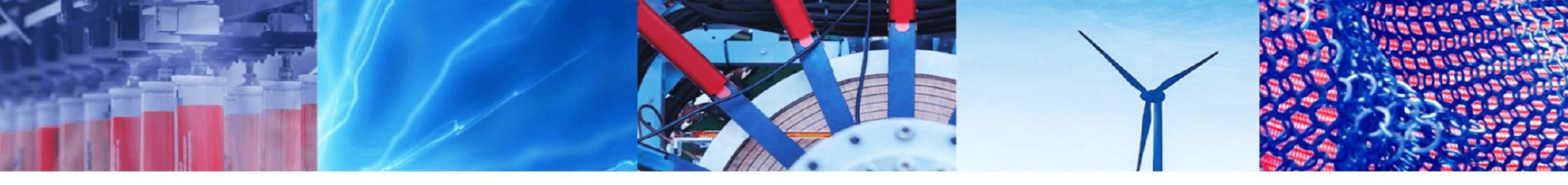

Research Article

\title{
Effect of gadolinia addition on the mechanical and physical properties of zirconia/ceria ceramics
}

\author{
Omyma H. Ibrahim ${ }^{1} \cdot$ Kolthoum I. Othman ${ }^{1} \cdot$ Ahmed A. Hassan $^{1} \cdot$ S. El-Houte ${ }^{1} \cdot$ M. El Sayed Ali ${ }^{1}$
}

Received: 27 July 2020 / Accepted: 22 September 2020 / Published online: 1 October 2020

(c) Springer Nature Switzerland AG 2020

\begin{abstract}
In this work, zirconia powders containing 5 and $10 \mathrm{~mol} \%$ ceria were prepared by co-precipitation method followed by doping with small amounts $(<1 \mathrm{~mol} \%)$ of gadolinia which stabilized the tetragonal phase. X-ray diffraction and scanning electron microscopy were used for phase analysis and microstructure examination, respectively. The sintered compacts showed fine grained, dense, tough and strong ceramics. Strength up to $795.8 \mathrm{MPa}$ and toughness of $17 \mathrm{MPa} \sqrt{\mathrm{m}}$ have been obtained. These ceramics showed higher toughness than yttria-doped tetragonal zirconia polycrystals (Y-TZP) and a higher strength than the ceria tetragonal zirconia polycrystals (Ce-TZP). The high fracture toughness was attributed to the tetragonal-to-monoclinic phase transformation which was associated with ferroelastic domain switching. The domain switching toughening has been discussed in view of Chevalier's model. Four-point bending strengths for the samples tested in the as cut state are higher than those tested in the as-sintered or the ground states.
\end{abstract}

Keywords Tetragonal zirconia · Transformation toughening $\cdot$ Gadolinia $\cdot$ Ceria $\cdot$ Mechanical and physical properties

\section{Introduction}

For engineering applications, ceramics should possess a high fracture toughness to assure safety and durability. Zirconia-based ceramics, stabilized with metal oxides such as yttria, ceria, magnesia, calcia, and others, have obtained increasing attention due to their superior mechanical properties. Additives used to stabilize zirconia not only produce crack-free zirconia, but also the sintered compact can retain the high temperature phase, i.e., the tetragonal phase at room temperature, where the equilibrium phase is monoclinic [1, 2]. Among all zirconia ceramics, yttria tetragonal zirconia polycrystals (YTZPs) are the most attractive, for wide range of energy and biomedical applications, due to their unusual combination of excellent mechanical properties (i.e., high strength and high fracture toughness), as well as low thermal conductivity and biocompatibility [3-10].
The use of a second dopant has been found useful to improve certain properties of zirconia-based ceramics. Doping yttria tetragonal zirconia polycrystals (YTZPs) with $\mathrm{CeO}_{2}$ or addition of alumina and silica were found to improve thermal stability upon aging at relatively low temperatures [11-15]. Moreover, it was found that the ceria addition to zirconia reduces its thermal conductivity, making this ceramic an alternative candidate to be used in thermal barrier coating applications [16]. Gadolinia and ytterbia addition to yttria-doped tetragonal zirconia increased the hardness and the stability of the tetragonal phase, but at the same time decreased the thermal conductivity [17]. Doping yttria tetragonal zirconia with $\mathrm{TiO}_{2}$ promoted grain growth and produced transparent ceramics [18]. It was found also that yttria addition to MgPSZ using simple techniques [19] produced a material with long-term thermal stability at relatively high temperatures, a property highly demanded in sensor applications. Addition of dopants like $\mathrm{MoO}_{3}$ to India-stabilized zirconia

Omyma H. Ibrahim, omyma_essam@yahoo.com | 'Metallurgy Department, NRC, Atomic Energy Authority, Cairo, Egypt. 
increased the hardness, ionic conductivity and the thermal expansion [20]. $\mathrm{La}_{2} \mathrm{O}_{3}$ addition to ceria-based solid electrolyte enhances its ionic conductivity and thermal stability [21]. The addition of a material having a high elastic modulus to YTZP, formed composites with improved strength and toughness [22], as a result of strong fiber-matrix interface $[22,23]$.

Tetragonal zirconia produced by doping with ceria (Ce-TZP) is a very attractive ceramic material, which possesses high fracture toughness [12, 24]. Whenever Ce-TPZ was prepared from pure precursors, it had relatively high fracture toughness but low strength. On the other hand, a commercial grade-starting additive powder of $\mathrm{CeCl}_{3}$ containing $7 \% \mathrm{LaCl}_{3}$-was found to produce sintered compacts of lower toughness and higher strength [14]. It was found in this latter case that a smaller amount of $\mathrm{CeO}_{2}$ ( $8 \mathrm{~mol} \%$ ) could stabilize the tetragonal phase, whereas $12 \mathrm{~mol} \%$ ceria is needed to stabilize the material made from pure precursors. This gave an indication that doping with a trivalent rare earth oxide such as lanthanum oxide could enhance the strength of ceria-doped tetragonal zirconia polycrystals (Ce-TPZ). Further, it has been shown that doping zirconia/6 $\mathrm{mol} \% \mathrm{CeO}_{2}$ with $1.5 \mathrm{~mol} \%$ gadolinia could stabilize the tetragonal phase [25], compared to the $12 \mathrm{~mol} \%$ Ceria which is the minimum amount of ceria required to stabilize the tetragonal phase zirconia ceramic as mentioned above.

In this work, zirconia-ceria ceramic powders with two different compositions were prepared. The effect of gadolinia additions (at percentages ${ }^{<} 1 \mathrm{~mol} \%$ ) on the physical and mechanical properties of the sintered compacts made from these ceramic powders were studied, as well as the toughening mechanisms.

\section{Experimental work}

Co-precipitated powders containing 5 and $10 \mathrm{~mol} \% \mathrm{CeO}_{2}$ were prepared from $0.2 \mathrm{M}$ mixed salt solutions containing the corresponding concentrations of zirconium oxychloride (Fluka Chemicals, UK, purity 99\%) and cerium nitrate (Rare Earth Corporation, purity 99\%). The coprecipitation was done at $\mathrm{pH}=9$, using ammonia solution for control, while stirring. The precipitate gels were dried, calcined at $600^{\circ} \mathrm{C}$, ground, wet ball-milled followed by sieving to produce ceria-doped zirconia powders. Ethanolic solutions of gadolinium nitrate (Rare Earth Corporation, purity 99\%) with different concentrations, were added and mixed with each of the above powders to produce zirconia powders containing $0.85 \mathrm{~mol} \%$ gadolinia $/ 5 \mathrm{~mol} \%$ ceria and $0.5 \mathrm{~mol} \%$ gadolinia/ $10 \mathrm{~mol} \%$ ceria (designated as $5 \mathrm{CeGd}$ and $10 \mathrm{CeGd}$ ), respectively. The mixed powders were then dried, calcined, ground and finally wet ball-milled once again.

Rectangular samples of $35 \mathrm{~mm}$ length, $8 \mathrm{~mm}$ width, and $2 \mathrm{~mm}$ thick were prepared by pressing at $100 \mathrm{MPa}$. They had green densities of $43 \%$ TD. The samples were then sintered in air at temperatures from $1400-1600^{\circ} \mathrm{C}$ for $2 \mathrm{~h}$. The sintered densities were obtained using Archimedes method, taking into account the open porosities if it existed. X-ray diffraction analysis (Shimadzu XRD-3A diffractometer with Cu ka Ni filter) was used for quantitative phase determination [26], where the monoclinic weight and volume fractions $X_{m}$ and $V_{m}$ were calculated using the following Eqs. (1 and 2), from the XRD peak intensities I.

$X_{m}=\frac{I_{m}(\overline{1} 11)+I_{m}(111)}{I_{m}(\overline{1} 11)+I_{m}(111)+I_{t}(111)}$

$v_{m}=\frac{P X_{m}}{1+(P-1) X_{m}}$

Here $P$ is a constant equal to 1.333 .

For microstructure examination, the samples were ground and polished using Abramin automatic grinding and polishing machine from Struers Denmark. The grinding and polishing media were diamond disks and diamond paste $(29 \mu \mathrm{m}, 7 \mu \mathrm{m}, 2-5 \mu \mathrm{m})$ under efficient fluid cooling. The samples were then thermally etched in air at $1350^{\circ} \mathrm{C}$ for $20 \mathrm{~min}$. The microstructure examination was done using a scanning electron microscope (SEM: JSM-5400 JEOL). The hardness and fracture toughness were measured using the Vickers Indentation Fracture technique (IF) on the mirror-polished sample surfaces. The polishing has been done with great care in order to minimize surface stress and to reduce tetragonal to monoclinic phase transformation on the samples' surfaces). Zwick Hardness Tester Germany at $300 \mathrm{~N}$ load was used. The Niihara's equation [27] was applied for the fracture toughness calculations,

$K_{1 C}=0.0726 P C^{-3 / 2}$

\section{And Vickers hardness}

$H v=0.47 \mathrm{P} / \mathrm{a}^{2}$

Here $P$ is the indentation load in Newton, a and $c$ are the indentation half diagonal and the half crack length in meter, $H v$ in $\mathrm{GPa}$ and $K_{1 \mathrm{C}}$ in $\mathrm{MPa} \sqrt{\mathrm{m}}$.

A four-point bend test was performed using LLOYD LR10KN universal testing machine with $10 / 20 \mathrm{~mm}$ loading/supporting spans, and $0.22 \mathrm{~mm} / \mathrm{min}$ cross-head speed for fracture strength determination. The bend strength has been calculated from the following equation: 
$\sigma_{f}=3 P_{f} L / 4 b h^{2}$

Here $\sigma_{f}$ is the bend strength in MPa. $L$ is the loading span, $b$ is the sample width, and $h$ is the sample thickness in meters. The cut surface was obtained by using Accutom-2 automatic cutting machine from Struers Denmark, using a thin diamond circular saw under very efficient cooling to avoid sample heating.

\section{Results and discussion}

\subsection{Densification, phases, and microstructure}

The base materials containing $5 \mathrm{~mol} \% \mathrm{CeO}_{2}(5 \mathrm{Ce})$ and $10 \mathrm{~mol} \% \mathrm{CeO}_{2}(10 \mathrm{Ce})$ showed low sintered densities. This was attributed to the small amount of $\mathrm{CeO}_{2}$ dopant, which could not stabilize the tetragonal phase completely. The densities obtained for these samples were corresponding to that of the monoclinic zirconia. The samples were weak and developed cracks, which resulted from the tetragonal to monoclinic phase transformation upon cooling from the sintering temperature. On the other hand, the gadolinia-doped samples, $5 \mathrm{CeGd}$ and $10 \mathrm{CeGd}$, showed high densities upon sintering, even at the lowest sintering temperature $\left(1400^{\circ} \mathrm{C} / 2 \mathrm{~h}\right)$, as shown in Table 1 . Sintering at higher temperatures, 1500 and $1600^{\circ} \mathrm{C}$, gave almost theoretical densities for both compositions.

Figure $1 \mathrm{a}$, $\mathrm{b}$ shows the $\mathrm{X}$-ray diffraction patterns for the as-sintered sample surface of $5 \mathrm{CeGd}$ and $10 \mathrm{CeGd}$ respectively, fired at $1400^{\circ} \mathrm{C}$. The XRD made on the surfaces of the samples sintered at a higher temperature, $1600^{\circ} \mathrm{C}$ are shown in Fig. 2 a, b. It can be seen that the tetragonal phase is dominant for the 10CeGd sample at both sintering temperatures (Figs.1b, 2b), while a small amount of the monoclinic phase appeared in the pattern for the $5 \mathrm{CeGd}$ sample, as shown in Figs.1a, 2a. It should be noted here that no cubic phase was detected in the XRD patterns, in the $2 \theta$ range from 73 to 75 . Only the tetragonal phase (004) and (400) lines existed. Even for the sample sintered at $1600 \mathrm{C}$ where there is a possibility of cubic phase formation, no cubic phase was detected but a tetragonal phase prevailed.

Table 1 The densities in \% TD of 5CeGd and 10CeGd samples, sintered at different temperatures

\begin{tabular}{lll}
\hline Sintering temperatures $\left({ }^{\circ} \mathrm{C}\right)$ & $5 \mathrm{CeGd}$ & $10 \mathrm{CeGd}$ \\
\hline 1400 & 97.4 & 99 \\
1500 & 99.4 & 99.6 \\
1600 & 99.5 & 99.4 \\
\hline
\end{tabular}
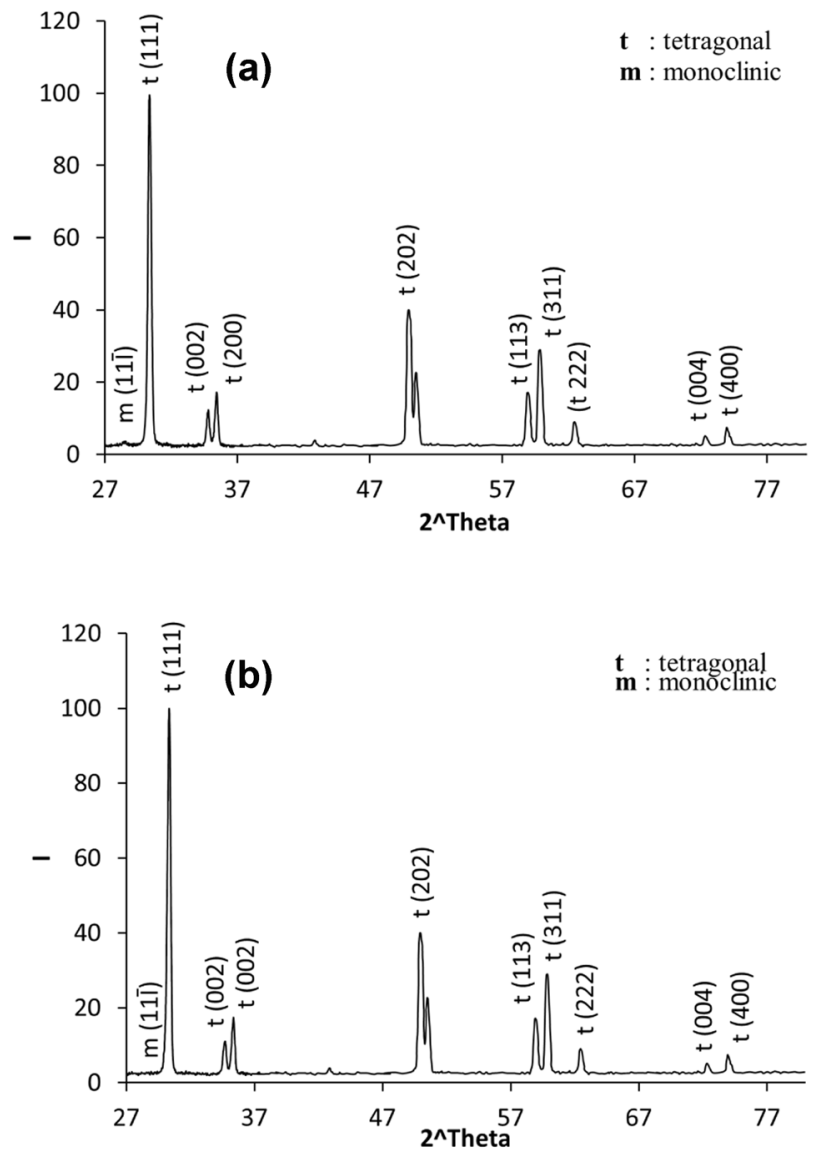

Fig. 1 XRD patterns made on the as-sintered sample surfaces fired at $1400^{\circ} \mathrm{C} / 2 \mathrm{~h}$ : a $5 \mathrm{CeGd}$, b $10 \mathrm{CeGd}$

Urabe et al. [25] proposed a phase diagram for ceria, gadolinia, and zirconia, by detecting the different phases present in the samples fired at $1600^{\circ} \mathrm{C}$ for $20 \mathrm{~h}$. Their results showed that the material containing $1 \mathrm{~mol} \%$ $\mathrm{Gd}_{2} \mathrm{O}_{3}$ and $3 \mathrm{~mol} \% \mathrm{CeO}_{2}$ had $96.4 \%$ of a tetragonal phase, while in the present work, the sintered samples containing $0.85 \mathrm{~mol}_{\%} \mathrm{Gd}_{2} \mathrm{O}_{3}$ and $5 \mathrm{~mol}^{\circ} \mathrm{CeO}_{2}$ showed almost completely tetragonal phase upon firing at $1600{ }^{\circ} \mathrm{C}$ for $2 \mathrm{~h}$. The slight difference is attributed to the variation in dopant concentration and the preparation method as well as the sintering time. The materials in [25] were prepared by co-precipitation from the homogeneous salt solutions of gadolinium, cerium, and zirconium in one step, while ours were made by adding an ethanolic solution of gadolinium nitrate to the mixed oxides of ceria/zirconia powder-previously prepared by co-precipitation.

Concerning the microstructure, fine-grained ceramics were obtained upon sintering at 1500 oC as shown in Fig. $3 \mathrm{a}$, b with $2 \mu \mathrm{m}$ and $1.5 \mu \mathrm{m}$ average grain sizes for the $5 \mathrm{CeGd}$ and $10 \mathrm{CeGd}$ materials, respectively. These 

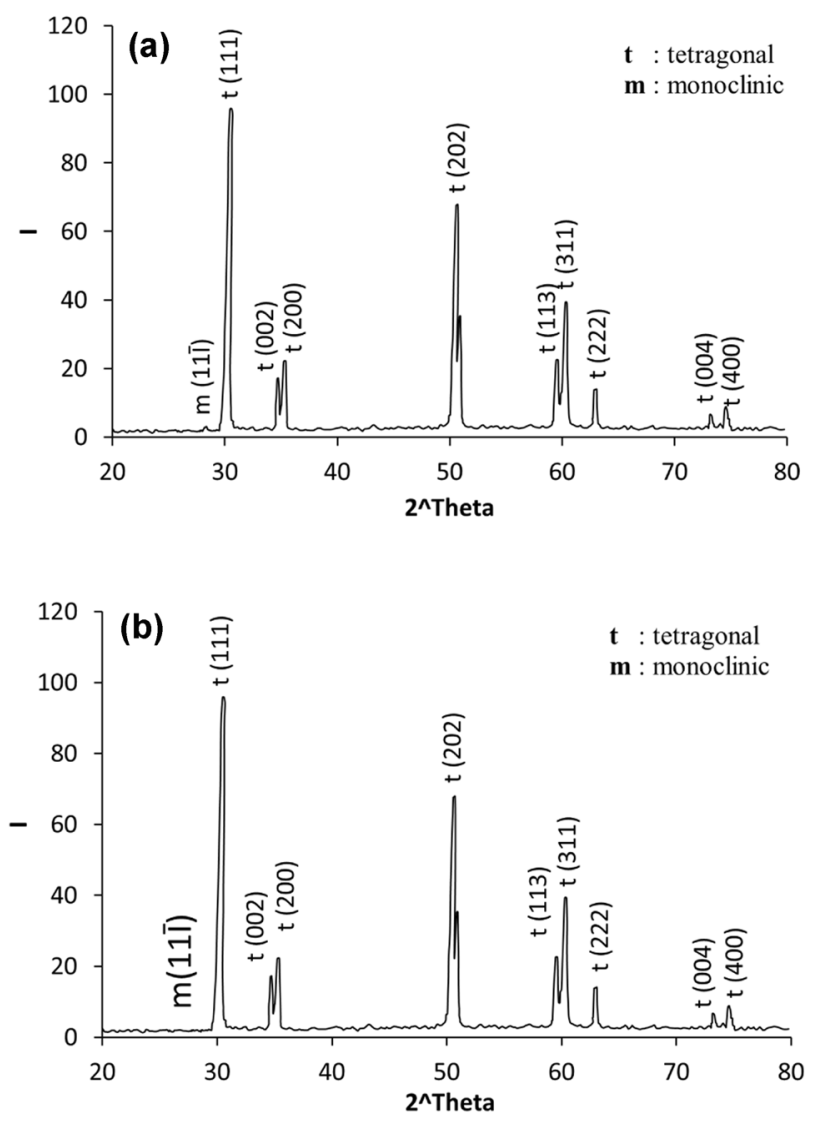

Fig. 2 XRD patterns made on the as-sintered sample surfaces fired at $1600^{\circ} \mathrm{C} / 2$ h: a $5 \mathrm{CeGd}, \mathbf{b} 10 \mathrm{CeGd}$

values are far below the $4 \mu \mathrm{m}$ obtained by Urabe et al. [25] when sintering at $1600^{\circ} \mathrm{C}$ for $20 \mathrm{~h}$. This indicates that the preparation technique used in the present work produced materials with smaller grain size, and consequently greater phase stability $[28,29]$.

\subsection{Mechanical properties}

The four points bend strength, fracture toughness and Vickers hardness results are given in Table 2, for the samples sintered at different temperatures. The values of the bend strength show that the gadolinia addition in small amounts enhanced the strength of the originally weak $5 \mathrm{Ce}$ and $10 \mathrm{Ce}$. The bend strength values were found to be higher than those obtained for the $12 \mathrm{~mol} \%$ ceria-doped zirconia $[12,24]$. However, it can be seen that both bend strength and Vickers hardness, decreased with sintering temperatures in agreement with previously published data [30, 31]. This might be due to grain size effect. It should also be noted that the hardness decreased slightly with the Vickers indentation loads.

Further, some of the samples prepared by pressureless sintering at $1400{ }^{\circ} \mathrm{C}$ were cut to study the effect of

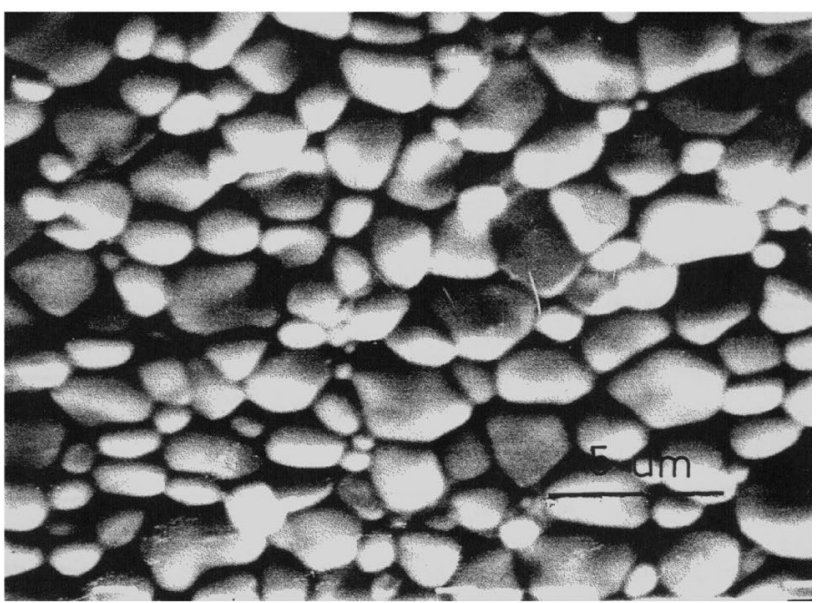

(a)

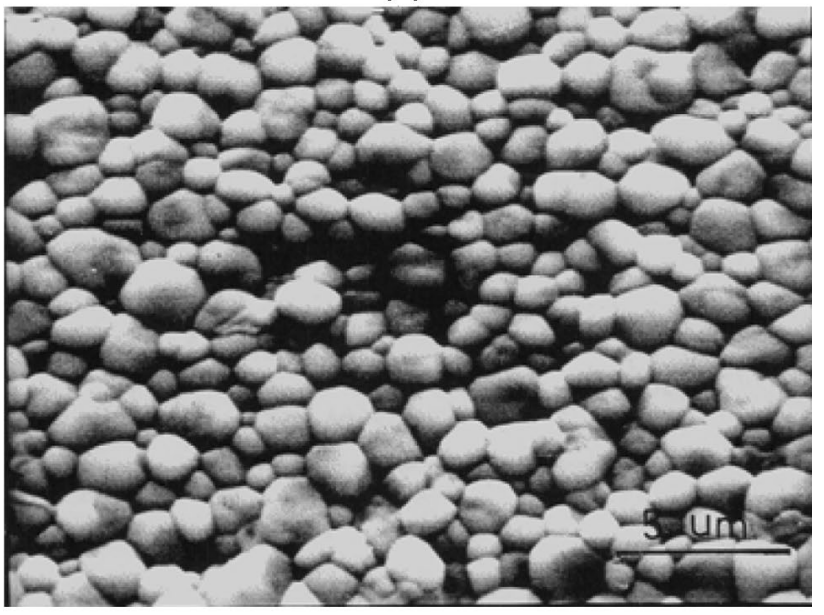

(b)

Fig. 3 SEM micrographs for the samples sintered at $1500^{\circ} \mathrm{C} / 2 \mathrm{~h}$ : a $5 \mathrm{CeGd}$, b $10 \mathrm{CeGd}$

cutting on the bend strength. It was found that, when the cut sample surface was subjected to the tensile stress during the four-point bend test, higher strength values were obtained, compared to the case when the ground surfaces were subjected to the tensile stress. Similar results have been obtained for yttria-doped zirconia (TZ3YA) [32].

Figure $4 \mathrm{a}, \mathrm{b}$ shows the XRD patterns made on the ground surfaces of $5 \mathrm{CeGd}$ and $10 \mathrm{CeGd}$ samples sintered at $1400^{\circ} \mathrm{C}$. It can be seen that grinding induced some tetragonal to monoclinic phase transformation. However, the tetragonal peak (111) does not show any anomaly or shoulder corresponding to a cubic phase; in contrast to what has been reported recently for zirconia composites doped with $\mathrm{Nd}_{2} \mathrm{O}_{3}$ and $\mathrm{Y}_{2} \mathrm{O}_{3}$ [33]. Figure $5 \mathrm{a}$, $b$ shows the XRD patterns made on the cut surfaces of $5 \mathrm{CeGd}$ and $10 \mathrm{CeGd}$ sintered at $1400^{\circ} \mathrm{C}$. The presence of the monoclinic phase indicated that cutting induced tetragonal to monoclinic phase transformation, same as in grinding and even greater. In addition, it can be seen 

bend strength $(\sigma)$, fracture toughness $\left(k_{1}\right)$, and Vickers hardness $(H v)$ results
Table 2 The four-point

\begin{tabular}{|c|c|c|c|c|c|}
\hline \multirow{2}{*}{\multicolumn{2}{|c|}{ Samples }} & \multicolumn{2}{|l|}{$5 \mathrm{CeGd}$} & \multicolumn{2}{|l|}{$10 \mathrm{CeGd}$} \\
\hline & & 1400 & 1600 & 1400 & 1500 \\
\hline \multirow[t]{2}{*}{$\sigma, \mathrm{MPa}$} & Cut & $652 \pm 40$ & $599 \pm 30$ & $795.8 \pm 50$ & $580 \pm 28$ \\
\hline & $\mathrm{Gr}$ & $630 \pm 38$ & $566 \pm 27$ & $706.7 \pm 44$ & $530 \pm 26$ \\
\hline$k_{l C}, \mathrm{MPa} \sqrt{ } \mathrm{m}$ & $13 \pm 0.3$ & $13.4 \pm 0.4$ & $12.8 \pm 0.25$ & $17.3 \pm 0.4$ & \\
\hline$H v, \mathrm{GPa}$ & $11.3 \pm 0.28$ & $10.8 \pm 0.24$ & $10.9 \pm 0.25$ & $10.5 \pm 0.2$ & \\
\hline
\end{tabular}
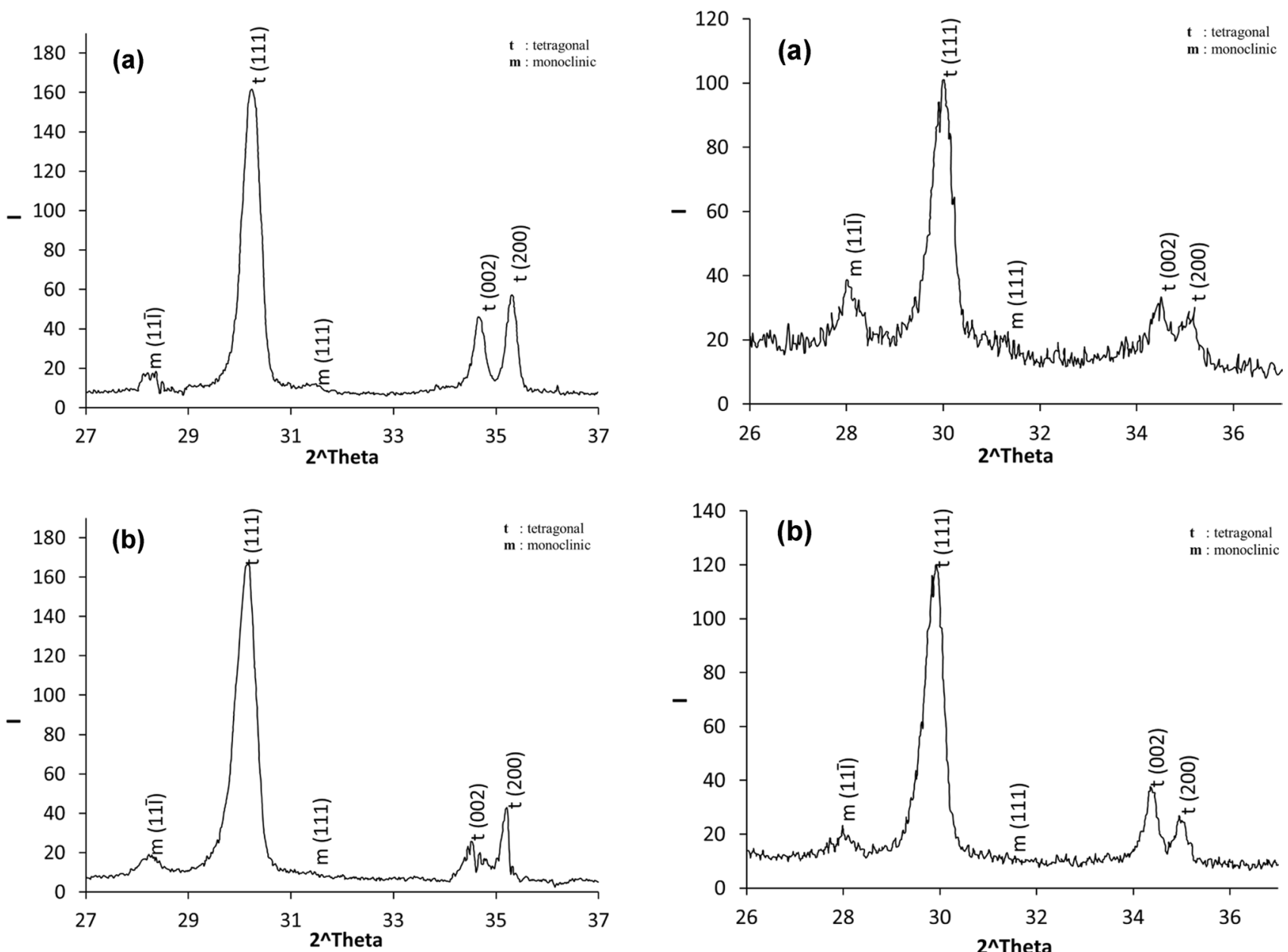

Fig. 4 XRD patterns made on the ground sample surfaces fired at $1400^{\circ} \mathrm{C} / 2$ h: a $5 \mathrm{CeGd}$, b $10 \mathrm{CeGd}$

that the intensity of the (002) line increases while that of the (200) line decreases. Table 3 summarizes the XRD analysis from which it can be seen that grinding induced phase transformation while cutting induced phase transformation as well as domain reorientation. The domain reorientation (domain switching) is the switching of the intensities of XRD lines (002) and (200). This has been previously observed on the cut surface of some tetragonal zirconia ceramics $[34,35]$.

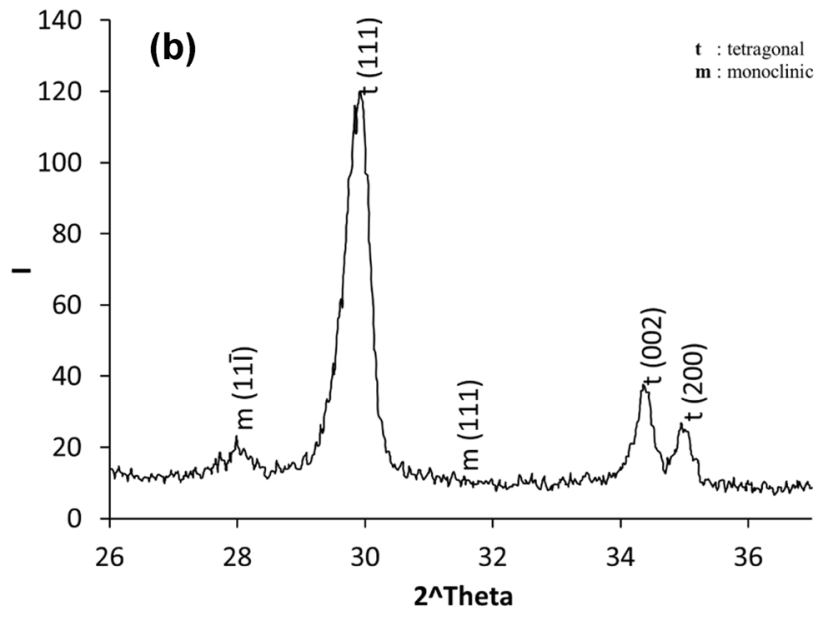

Fig. 5 XRD patterns made on cut sample surfaces fired at $1400{ }^{\circ} \mathrm{C} / 2 \mathrm{~h}$, a $5 \mathrm{CeGd}$, b $10 \mathrm{CeGd}$

The above-mentioned XRD results and analysis can explain the higher strength values obtained for the as cut samples compared with those obtained for the as ground samples. The higher strength values might be attributed to the larger portion of constrained expansion volume resulting from the phase transformation on the as cut rather than on the as ground surfaces.

Figure 6 shows the Weibull plot for the bend strengths of the samples $10 \mathrm{CeGd}$ sintered at $1400^{\circ} \mathrm{C}$ for $2 \mathrm{~h}$, where 
Table 3 XRD analysis for the samples sintered at $1400^{\circ} \mathrm{C} / 2 \mathrm{~h}$ with different surface status

\begin{tabular}{llll}
\hline Sample & $5 \mathrm{CeGd}$ & $10 \mathrm{CeGd}$ & \\
\hline As sintered & $\mathrm{m} \%$ & 2 & 0 \\
& $\mathrm{I}(002) / \mathrm{I}(200)$ & 0.7 & 0.58 \\
As ground & $\mathrm{m} \%$ & 9.5 & 8.4 \\
& $\mathrm{I}(002) / \mathrm{I}(200)$ & 0.78 & 0.53 \\
As cut & $\mathrm{m} \%$ & 20 & 10 \\
& $\mathrm{I}(002) / \mathrm{I}(200)$ & 1.2 & 1.54 \\
\hline
\end{tabular}

m \%: monoclinic \%

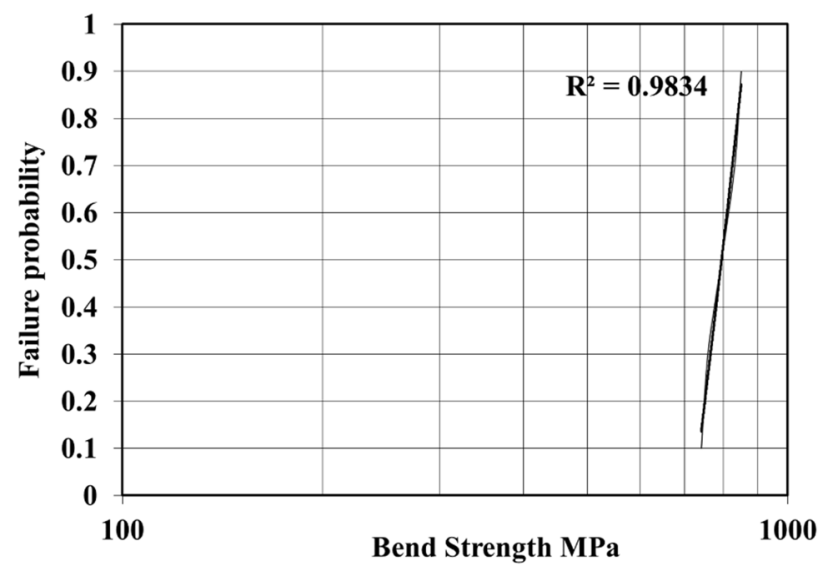

Fig. 6 The Weibull plot (semi-log plot) for the bend strengths of the samples $10 \mathrm{CeGd}$ sintered at $1400^{\circ} \mathrm{C} / 2 \mathrm{~h}$

the side of each sample exposed to the tensile stress was the cut surface. From the figure, a mean bend strength of 795.8 MPa and a high Weibull modulus equal to 34 were obtained.

\subsection{Toughening mechanisms}

\subsubsection{Transformation toughening}

Transformation toughening is the increase in resistance to crack propagation, which results from the martensitic tetragonal to monoclinic phase transition. This occurs ahead of the crack tip in the process zone and is characterized by microcrack formation. From Tables 2 and 3, an increase in the bend strength with the formation of monoclinic phase on the as cut sample surfaces can be observed. Also, the fracture toughness (the stress intensity factor $\mathrm{K}_{\mathrm{IC}}$ ) for the sample $5 \mathrm{CeGd}$ is greater than that for the sample $10 \mathrm{CeGd}$; where the cut and the ground surfaces show more monoclinic content in the former than in the later. The stresses applied by grinding and cutting trigger the tetragonal to monoclinic phase transformation on both the ground and cut sample surfaces. This phase transformation, as mentioned above, is accompanied by volume expansion in these sample surfaces, putting them under compression which creates a stress field acting in opposition to the stress field that promotes the propagation of the crack. Consequently, the bend stress increases to exceed these compression stresses.

An enhancement in toughness is obtained because the energy associated with crack propagation is dissipated both in the tetragonal/monoclinic transformation and in overcoming the compression stresses due to the volume expansion. The applied stress intensity factor $K_{I C}$ surpasses the real intensity factor at the crack tip $K_{\text {ltip }}$, by a $K_{l s h}$-stress intensity factor-due to crack tip shielding by the transformation in the process zone. This in fact acts to close the crack or to resist its opening and propagation. The $K_{l s h}$ is proportional to the applied $K_{l,}$ and the amount of phase transformation ahead of the crack tip which corresponds to the amount of transformable tetragonal phase present in the material. The following equation of Chevalier et al. [36], expresses the relations between $K_{l C^{\prime}}$ $K_{\text {ltip }}$ and $K_{l s h}$.

$K_{\text {ltip }}=K_{l C}-K_{\text {lsh }}$

where

$K_{l s h}=C_{s h} K_{l C}$

$C_{s h}=\frac{0.214 E V_{f} e^{T}(1+v)}{(1-v) \sigma_{m}^{c}} \frac{\sqrt{3}}{12 \pi}$

$E$ is the Young's modulus (GPa), $V_{f}$ the volume fraction of transformable particles, $e^{T}\left(T\right.$ in $\left.\mathrm{K}^{\circ}\right)$ is the volume of dilatation associated with the transformation, $v$ is the Poisson's ratio, and $\sigma_{m}^{C}(\mathrm{MPa})$ is the critical local stress leading to phase transformation. This equation could be made use of qualitatively rather than quantitatively because of the difficulties encountered in determining the parameters.

From the above equation, it can be seen clearly that the transformation toughening, is a function of the volume fraction of the transformable tetragonal phase present in the samples; rather than the whole tetragonal phase present. This is in agreement with previously reported results by Lin et al. [37] which related the increase in fracture toughness to the increase in transformability or operation relevant toughening mechanisms. The increase in bend strength obtained for the samples tested when the cut surface was the one subjected to tension is the result of the high compressive stress induced by cutting. This in fact made the sample to fracture at a higher stress which in turn induced more tetragonal to monoclinic phase transformation. Figure 7 shows $50 \%$ monoclinic phase on the fracture surface for the sample $5 \mathrm{CeGd}$ sintered at $1400^{\circ} \mathrm{C}$. 


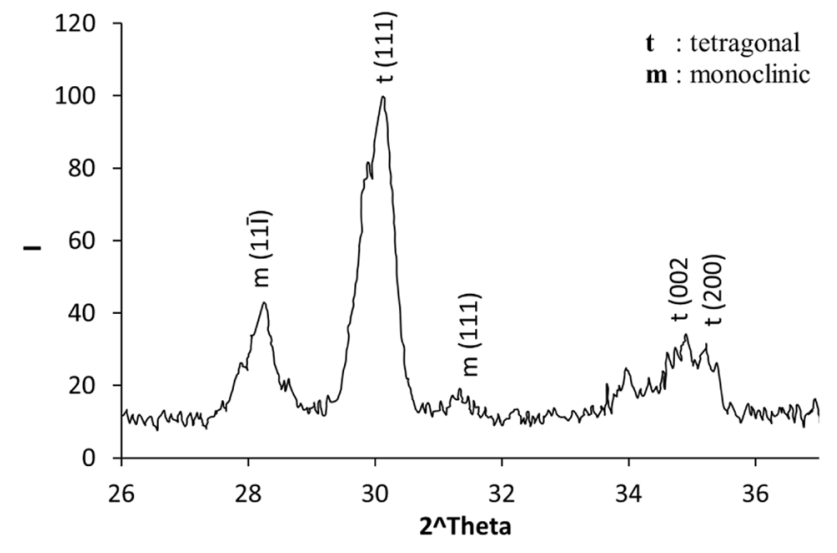

Fig. 7 The XRD made on the fracture surface of the cut 5CeGd sample sintered at $1400^{\circ} \mathrm{C}$

\subsubsection{Domain switching toughening}

In principle, both the domain switching and transformation toughening can occur simultaneously during crack propagation. It can be seen from Fig. 5 a, b for the XRD patterns made on the as cut sample surfaces that: The intensity of the line (002) increased and that of the line (200) decreased; so that the ratio of $I(002) / /(200)$ became greater than one, while it was less than one for the assintered and the ground samples (Table 3 ). The domain switching is ferroelastic and the toughening mechanism is a ferroelastic transformation; which is related to the change from one equilibrium state to another by domain reorientation. Since both are stress assisted, one may ask whether it is the tetragonal to monoclinic transformation or the domain switching. Actually, they can occur simultaneously. The difference between them is that the transformation toughening requires the material to contain a substantial amount of transformable tetragonal phase, while domain switching occurs in transformable phase and non-transformable phase as well. This agrees with the results of Mehta, K. et al. [38] who showed that the domain switching is not related to transformation, reversible or otherwise, but can be explained by ferroelastic domain switching. The XRD made on the fracture surface of the cut sample (Fig. 7) showed a change in the intensity of the (002) line relative to the (200) line indicating that ferroelastic transformation takes place along with transformation toughening.

It has been reported that the intensity ratio $/(002) / /(200)$ changed upon applying electric field for lead titanate zirconate PZT $(95 / 5)[39,40]$. The fracture toughness of PZT increased after poling, which resulted in domain reorientation [41]. The contribution of the ferroelastic domain switching to the stress intensity factor $K_{I C}$ is small. It was approximately estimated to be in the order of $2 \mathrm{MPa} \sqrt{\mathrm{m}}$, or less for tetragonal zirconia ceramics [36]. This might be explained by the small increase of the intensity of the line (002) over the line (200) shown on Fig. 7. In spite of the difficulty of doing XRD on such a very rough and rather irregular surface, the results indicated that a ferroelastic transformation might exist.

\section{Conclusions}

The effect of gadolinia addition to unstabilized zirconia doped with ceria ceramics has been studied. Doping $5 \mathrm{Ce}$ and $10 \mathrm{Ce}$ zirconia with small amounts of gadolinia: $0.85 \mathrm{~mol} \%$ and $0.5 \mathrm{~mol} \%$, respectively, could stabilize the tetragonal phase and produce strong and dense ceramics. The method of doping $5 \mathrm{Ce}$ and $10 \mathrm{Ce}$ previously prepared by co-precipitation with gadolinia powder led to the production of fine-grained ceramics with high stability of the tetragonal phase and consequently high strength. Strengths up to $795.8 \mathrm{MPa}$ could be obtained when the cut surfaces were subjected to the tensile stress during the bending test. High fracture toughness of $17 \mathrm{MPa} \sqrt{\mathrm{m}}$ was obtained for the $10 \mathrm{CeGd}$ material sintered at $1500^{\circ} \mathrm{C}$ for $2 \mathrm{~h}$. The gadolinia-doped materials prepared during this work are tougher than the YTZP ceramics and stronger than the Ce-TZP ceramic. The XRD showed substantial increase in the intensities of the lines (111) and (111) of the monoclinic phase, besides an increase in the intensity of the line (002) relative to the line (200) on the as the cut and fracture surfaces. The toughening mechanisms are mainly transformation toughening and possibly simultaneously ferroelastic domain switching toughening. The domain switching toughening has been discussed in view of Chevalier's model. Extensive work and more detailed studies have to be done on the ferroelastic transformation toughening of the tetragonal zirconia ceramics. This might be an interesting subject for future work.

\section{Compliance with ethical standards}

Conflict of interest I and on behalf of all the authors of the paper entitled: "Effect of gadolinia addition on the mechanical and physical properties of zirconia/ceria ceramics". State that, its whole content is not a subject to any type of conflict interest.

\section{References}

1. Saridag S, Tak O, Alniacik G (2013) Basic properties and types of zirconia: an overview. World J Stomatol 12(3):40-47

2. Bona $A D$, Pecho OE, Alessandretti $R$ (2015) Zirconia as a dental biomaterial: review. Materials 8:4978-4991

3. Dahl GT, Döring S, Krekeler T, Janssen R, Ritter M, Weller H, Vossmeyer T (2019) Alumina-doped zirconia submicro-particles: 
synthesis, thermal stability, and microstructural characterization. Materials 12:2856

4. Panthi D, Hedayat N, Du Y (2018) Densification behavior of yttriastabilized zirconia powders for solid oxide fuel cell electrolytes. J Adv Ceram 7(4):0-0

5. Gommeringer A, NölleL KF, Gadow R (2019) Yttria ceria co-stabilized zirconia reinforced with alumina and strontium hexaaluminate. Appl Sci 9:729

6. Abd El-Ghany OS, Sherief AH (2016) Zirconia based ceramics, some clinical and biological aspects: review. Fut Dent J 2:55-64

7. Hansen TL, Schriwer C, Øilo M, Gjengedal H (2018) Monolithic zirconia crowns in the aesthetic zone in heavy grinders with severe tooth wear-an observational case-series. J Dentist 72:14-20

8. Kontonasaki E, Rigos AE, llia C, Istantsos T (2019) Monolithic zirconia: an update to current knowledge. Optical properties, wear, and clinical performance. Dentist J 7:90

9. Ragurajan D, Golieskardi M, Satgunam $M$, Hoque ME, Ng AMH, Ghazali MJ, Ariffin AK (2018) Advanced 3Y-TZP bioceramic doped with $\mathrm{Al}_{2} \mathrm{O}_{3}$ and $\mathrm{MnO}_{2}$ particles potentially for biomedical applications: study on mechanical and degradation properties. J Mater Res Tech 7(4):432-442

10. Sultana N, Bilkis K, Azad R, Qadir MR, Gafur MA, Alam MZ (2018) Yttria stabilized tetragonal zirconia ceramics: preparation, characterization and applications. Bangladesh J Sci Ind Res 53(2):111-116

11. Sato T, Shimada M (1985) Transformation of ceria-doped tetragonal zirconia polycrystals by annealing in water. Am Ceram Soc Bull 64:1382-1389

12. Tsukuma K (1986) Mechanical properties and thermal stability of $\mathrm{CeO}_{2}$ containing tetragonal zirconia polycrystals. Am Ceram Soc Bull 65:1386-1390

13. Sato T, Ohataki S, Endo T, Shimada M (1988) Improvement of the thermal stability of Yttria-doped tetragonal Zirconia polycrystals by alloying with various oxides. Advances in Ceramics. vol. 24: Science and Technology of Zirconia III. Ed. by S. Somiya, N. Yamamato and $\mathrm{H}$. Hanagida,

14. Tsukuma K, Shimada M (1985) Strength, fracture toughness and vickers hardness of $\mathrm{CeO}_{2}$-stabilized tetragonal $\mathrm{ZrO}_{2}$ polycrystals Ce-TZP. J Mater Sci 20:1178-1184

15. Samodurova A, Kocjan A, Swain MV, Kosmac T (2014) The combined effect of alumina and silica co-doping on the ageing resistance of 3Y-TZP bioceramics. Acta Biomater 11:477-487

16. Gul SR, Khan M, Zeng Y, Lin M, Wu B (2018) Electronic band structure variations in the ceria doped zirconia: a first principles study. Materials 11:1238

17. Guo L, Guo H, Gong S, Xu H (2013) Improvement on the phase stability, mechanical properties and thermal insulation of $\mathrm{Y}_{2} \mathrm{O}_{3}$-stabilized $\mathrm{ZrO}_{2}$ by $\mathrm{Gd}_{2} \mathrm{O}_{3}$ and $\mathrm{Yb}_{2} \mathrm{O}_{3}$ co-doping. Ceram Int 39(8):9009-9015

18. Tsukuma $\mathrm{K}$, Takahata $\mathrm{T}$, Tsukidate $\mathrm{T}$ (1988) Transparent $\mathrm{TiO}_{2}-\mathrm{Y}_{2} \mathrm{O}_{3}-$ $\mathrm{ZrO}_{2}$ ceramics. Advances in Ceramics, vol. 24: Science and Technology of zirconia III. Ed. by S. Somiya, N. Yamamato and H. Hanagida

19. Sørensen OT, El-Sayed Ali M (1991) Structural ceramics based on nonstoichiometric zirconia-high temperature long term stability materials for oxygen sensor applications prepared by co-doping. Solid State lonics 49:155-159

20. Piva RH, Piva DH, Montedo ORK, Morelli MR (2016) Improving physical properties of cubic $\ln \mathrm{O}_{15}$-stabilized zirconia by alloying with $\mathrm{MoO}_{3}$. J Alloy Compd 685:593-603

21. Rafiquea A, Razaa R, Arifin NAM, Ullaha K, Alia A, Wilckensc S-R (2018) Electrochemical and thermal characterization of doped ceria electrolyte with lanthanum and zirconium. Ceram Int 44(6):6493-6499

22. Ibrahim OH, Othman $\mathrm{Kl}$, Hassan AA, El-Houte S, El Sayed AM (2020) Synthesis and mechanical properties of zirconia-yttria matrices/ alumina short fiber composites. Arab J Sci Eng 45:4959-4965
23. An J, Zhao J, Su ZG, Wen Z, Xu DS (2015) Microstructure and mechanical properties of ZTA ceramic-lined composite pipe prepared by centrifugal-SHS. Arab J Sci Eng 40(9):2701-2709

24. El-Sayed Ali M, El-Houte S, Sørensen OT (1990) Properties of ceria doped tetragonal zirconia ceramics prepared by coprecipitation technique. In: Proceedings of the11th Risø International Symposium on Metallurgy and Materials Science Structural Ceramics, Microstructure and properties. Ed. by: J-J. Bentzen, J. BildeSørensen, N. Christiansen, A. Horsewell and B. Ralph, Risø, Denmark

25. Urabe K, Monma J, Ikawa H, Udagawa S (1988) Thermal stability of tetragonal zirconia in the system $\mathrm{ZrO}_{2}-\mathrm{Gd}_{2} \mathrm{O}_{3}-\mathrm{CeO}_{2}$. Sci Cerams 14, Ed. by D. Taylor

26. Toraya H, Yoshimora M, Somiya S (1984) Calibration for quantitative determination of the monoclinic tetragonal $\mathrm{ZrO}_{2}$ system by X-ray diffraction. J Am Ceram Soc 67:C119-C121

27. Niihara K, Morena R, Hasselman D (1982) Evaluation of $K_{\mathrm{IC}}$ of brittle solids by the indentation method with low crack-to-indent ratio. $J$ Mater Sci Lett 1:13-16

28. Gupta TK, Lange FF, Chtold JH (1978) Effect of stress-induced phase transformation on the properties of polycrystalline zirconia containing metastable tetragonal phase. J Mater Sci 13:1464-1470

29. Becher PF, Swain MV (1992) Grain-size-dependent transformation behavior in polycrystalline tetragonal zirconia. J Am Ceram Soc 75(3):493-502

30. Stawarczyk B, Özcan M, Hallmann L, Ender A, Mehl A, Hämmerlet CHF (2013) The effect of zirconia sintering temperature on flexural strength, grain size, and contrast ratio. Clin Oral Invest 17:269-274

31. Awaji H, Matsunag T, Choi S-M (2006) Relation between Strength, fracture toughness, and critical frontal process zone size in ceramics. Mater Trans 47(6):1532-1539

32. El-Sayed Ali M, Sørensen OT (1988) Effect of cutting on fracture strength of Yttria partially stabilized Zirconia. Risø-M-2682

33. Gommeringer A, Kern F, Gadow R (2018) Enhanced mechanical properties in ED-machinable zirconia-tungsten carbide composites with yttria-neodymia co-stabilized zirconia matrix. Ceramics 1:26-37

34. Virkar AN (1988) Toughening mechanism in tetragonal zirconia polycrystalline (TZP) ceramics. Advances in ceramics, vol.24: Science and Technology of Zirconia III. Ed. by S.Somiya, N. Yamamato and $\mathrm{H}$. Hanagida

35. Kitano Y, Mori Y, Ishitani A, Masaki T (1989) Structural changes by compressive stresses of $2.0 \mathrm{~mol} \%$-Yttria- stabilized tetragonal zirconia polycrystals. J Am Ceram Soc 72(5):854-55

36. Chevalier J, Gremillard L, Virkar AV, Clarke DR (2009) The tetragonal-monoclinic transformation in zirconia: lessons learned and future trends. J Am Ceram Soc 92(9):1901-1920

37. Lin J-D, Duh JD (2003) Fracture toughness and hardness of ceria and yttria doped tetragonal zirconia ceramics. J Mat Chem Phys 78:253-261

38. Mehta K, Jue JF, Virkar AV (1990) Grinding-induced texture in ferroelastic tetragonal zirconia. J Am Ceram Soc 73(6):1777-1779

39. Li X, Shih WY, Vartuli JS, Milius DL, Aksay IA, Shih W-H (2002) Effect of a transverse tensile stress on the electric-field-induced domain reorientation in soft PZT: in situ XRD study. J Am Ceram Soc 85(4):844-850

40. Kawasaki T, Ito T, InamuraY, Nakatani T, Harjo S, Gong W, Iwahashi T, Aizawa K (2015) Neutron diffraction study of piezoelectric material under cyclic electric field using event recording Technique. JAEAConf-002: 528-531

41. Lan CF, Nie HC, Chen XF, Wang JX, Wang GS, Dong XL, Liu YS, He $\mathrm{HL}$ (2013) Effects of poling state and pores on fracture toughness of $\mathrm{Pb}\left(\mathrm{Zr}_{0.95} \mathrm{Ti}_{0.05}\right) \mathrm{O}_{3}$ ferroelectric ceramics. Adv Appl Ceram 1-5

Publisher's Note Springer Nature remains neutral with regard to jurisdictional claims in published maps and institutional affiliations. 